\title{
Novel PAX6 variant in a family with ophthalmologic, pancreatic, and olfactory features
}

\author{
Kristen L. Buehne, ${ }^{1}$ Sarah Hart, ${ }^{1}$ Bradley Williams, ${ }^{2}$ and Jennifer L. Cohen ${ }^{1}$ \\ ${ }^{1}$ Department of Pediatrics, Division of Medical Genetics, Duke University School of Medicine, Durham, North \\ Carolina 27710, USA; ${ }^{2}$ GeneDx, Inc., Gaithersburg, Maryland 20877, USA
}

\begin{abstract}
Variants in the PAX6 gene have been associated with ophthalmologic, neurologic, and pancreatic differences. We report on a proband, mother, and affected brother who presented with congenital cataracts and glaucoma at a young age. Nonocular findings are also reported among these family members. After a congenital cataracts next-generation sequencing (NGS) gene panel was found to be nondiagnostic in 2016, a more expanded panel in 2020 revealed a novel variant: c.178T > A; p. Tyr60Asn in exon 6 of the PAX6 gene in the proband. The variant is also present in the affected mother and affected brother; it is absent in an unaffected brother. The clinical findings of these three relatives, in conjunction with their genetic testing and the associated PAX6 features reported in the literature, suggest that this novel familial variant may be an underlying etiology for these individuals' ophthalmologic, pancreatic, and olfactory symptoms.
\end{abstract}

Corresponding author: jennifer.L.cohen@duke.edu

(c) 2022 Buehne et al. This article is distributed under the terms of the Creative Commons Attribution-NonCommercial License, which permits reuse and redistribution, except for commercial purposes, provided that the original author and source are credited.

Ontology terms: congenital nuclear cataract; diabetes mellitus; partial anosmia

Published by Cold Spring Harbor Laboratory Press

doi:10.1101/mcs.a006149

\section{CASE PRESENTATION}

The PAX6 gene encodes a DNA-binding transcriptional factor important for development of the eyes, brain, and pancreas (Xie et al. 2013). Disruption of PAX6 is known for causing forms of aniridia, keratitis, glaucoma, cataracts, foveal hypoplasia, and microphthalmia (Lee et al. 2008). Neurologic differences, including intellectual disability, cerebellar ataxia, and anosmia, and pancreatic abnormalities, such as diabetes mellitus, have also been reported (Lima Cunha et al. 2019). We present a novel PAX6 variant found among three family members with ocular, neurologic, and endocrine symptomatology (Table 1).

Most notably, an individual (proband), her mother, and brother were found to have bilateral congenital cataracts in early infancy. These were subsequently removed at $2 \mathrm{mo}, 9 \mathrm{mo}$, and $3 \mathrm{mo}$ of age, respectively. The proband had lens implantations at the time of this surgery. The mother does not have lens implants. The affected brother had lens implantations at 7 years of age. The proband was diagnosed with glaucoma at 6 mo of age. Her mother was diagnosed at 18-19 yr old, and her brother at $6 \mathrm{yr}$ old. Other symptoms experienced by one or more of these related individuals include anosmia, learning difficulties, pancreatitis in adulthood, pancreatic underdevelopment and hypoglycemia in infancy, and type II diabetes mellitus. Figure 1A displays a three-generation pedigree for this family following testing of the proband's first-degree relatives for the PAX6 variant. The pedigree shows three affected individuals and one unaffected relative, with their associated genetic testing results. Table 1 details the phenotype of the proband and the two relatives who were found to harbor this variant. 


\begin{tabular}{|c|c|c|c|c|}
\hline Features presumed to be due to PAX6 & Proband & Mother & Sibling & Alternate explanation \\
\hline \multicolumn{5}{|l|}{ Ophthalmologic } \\
\hline Bilateral congenital cataracts & Yes & Yes & Yes & \\
\hline Early-onset glaucoma & Yes & Yes & Yes & \\
\hline Stromal hypoplasia of the iris & Yes & Yes & No & \\
\hline Nystagmus & Yes & No & No & \\
\hline Exotropia & Yes & No & Yes & \\
\hline Fovea plana & Yes & No & No & \\
\hline Serous retinal detachment & No & No & Yes & \\
\hline Coloboma & No & No & No & \\
\hline Optic nerve hypoplasia & No & No & No & \\
\hline Aniridia & No & No & No & \\
\hline Keratitis & No & No & No & \\
\hline Microcornea & No & Yes & No & \\
\hline \multicolumn{5}{|l|}{ Neurologic } \\
\hline Reduced olfaction & Yes & Yes & No & \\
\hline Migraine & Yes & No & No & \\
\hline Myoclonic tremor & Yes & No & No & \\
\hline Learning difficulties & Yes & Yes & Yes & \\
\hline Absent pineal gland & No & No & No & \\
\hline Hypoplastic anterior commissure & No & No & No & \\
\hline Hypoplastic corpus callosum & No & No & No & \\
\hline \multicolumn{5}{|l|}{ Endocrine } \\
\hline Type II diabetes mellitus & No & Yes & No & \\
\hline Pancreatitis & No & No & Yes & \\
\hline Neonatal pancreatic underdevelopment & No & No & Yes & \\
\hline \multicolumn{5}{|l|}{ Novel clinical features } \\
\hline Hypermobile joints & Yes & No & No & \multirow{2}{*}{$\begin{array}{l}\text { Family history of connective } \\
\text { tissue disease on maternal } \\
\text { and paternal sides }\end{array}$} \\
\hline History of orthodontic headgear & Yes & No & No & \\
\hline Asthma with decreased lung capacity & Yes & No & No & Unrelated \\
\hline Sinus tachycardia with syncope & Yes & No & No & Unrelated \\
\hline Hemochromatosis & No & No & Yes & Unrelated \\
\hline
\end{tabular}

Findings highlighted in green are those reported in Online Mendelian Inheritance in Man (OMIM) in association with pathogenic PAX6 variants.

\section{TECHNICAL ANALYSIS}

All individuals provided consent for genetic testing, and affected individuals provided written consent for inclusion in this manuscript.

Genetic testing using a congenital cataract next-generation sequencing (NGS) panel was nondiagnostic for the proband in 2016. An NGS gene panel performed in 2020 included 86 genes associated with cataracts and revealed a heterozygous variant of uncertain significance (VUS), p.Tyr60Asn in exon 6 of PAX6 (NM_000280.3 c.178T >A), which has now been reclassified as likely pathogenic, based on PM1, PM2_P, PP3, PP4, and PP1 evidence. 
A

\section{Key}

Congenital cataracts and early-onset glaucoma

Miscarriage $\mid \mathbf{m}$ |س

Marfan Syndrome

Retinitis Pigmentosa* $\mathbb{H}$

Dysgraphia ……

Autism spectrum disorder $\square$

*Disease and symptoms reported by family, withou

documentation of genetic testing.

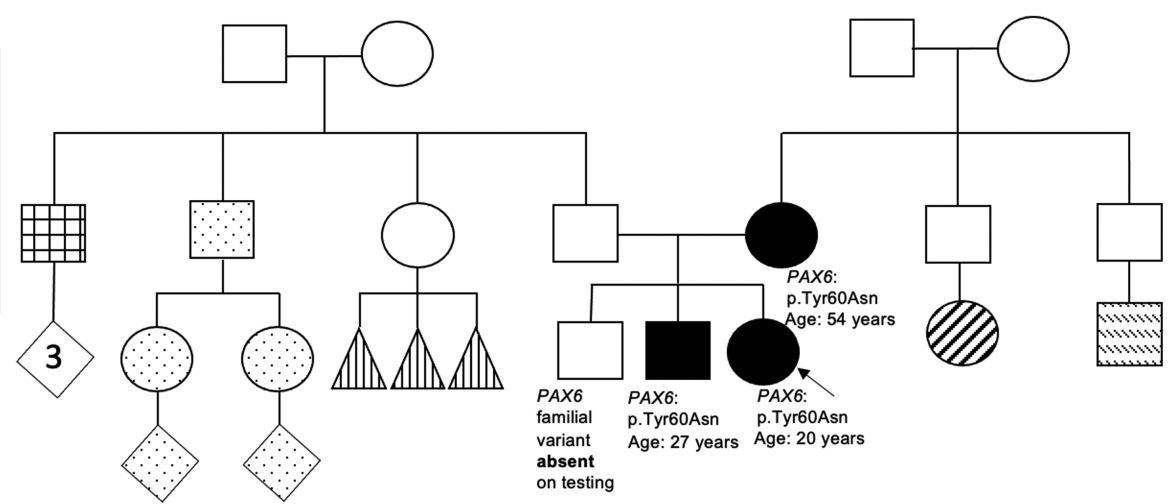

B

PAX6 c.178T>A; p.Tyr60Asn

TAT >AAT

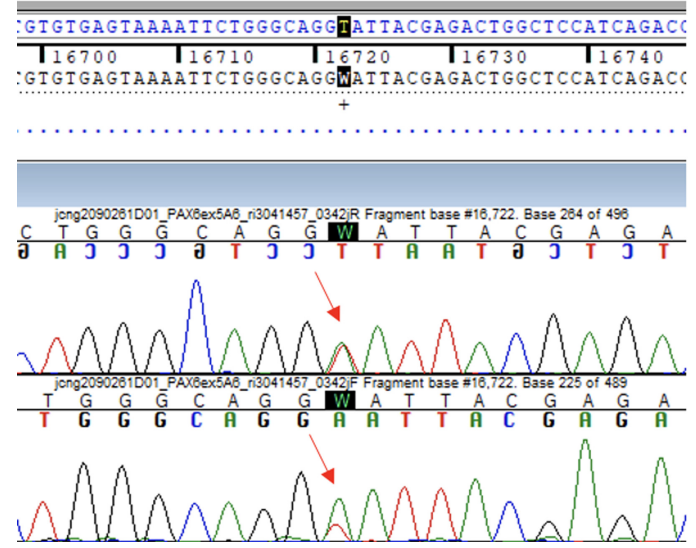

Reference Sequence

Proband's Consensus Sequence

(From raw data reads)

Proband

Complement to Reverse Sequence

Proband

Reverse Sequence

Proband

Forward Sequence

Figure 1. (A) A pedigree of the proband (marked by an arrow) and her family members. PAX6 testing results are denoted next to the proband, her mother, the affected brother, and unaffected brother. Of note, the unaffected brother tested negative for the novel PAX6 variant. Other diseases and symptoms among the family are denoted by their respective shadings. (B) A sequence chromatogram depicting forward and reverse traces obtained by capillary sequencing of PAX6, exon 6. The arrows indicate the presence of the heterozygous c.178T > A; p.Tyr60Asn variant. Data obtained by GeneDx, 2021, Cataract Panel.

NGS testing was performed using a proprietary targeted capture system developed by GeneDx for NGS with copy-number variation (CNV) calling (NGS-CNV). The enriched targets were simultaneously sequenced with paired-end reads on an Illumina platform. Bidirectional sequence reads were assembled and aligned to reference sequences based on National Center for Biotechnology Information (NCBI) RefSeq transcripts and human genome build GRCh37/UCSC hg19. After gene-specific filtering, data were analyzed to identify sequence and most copy-number variants. Capillary sequencing was performed to confirm the reported variant in the proband (Fig. 1B) and in the two other affected family members. The analysis software program used was Sequencher 4.9, Gene Codes Corporation. Table 2 details the PAX6 variant segregating with the disease in this family. Table 3 details the damage scores and ranges of the in silico analysis. Each of the three algorithms used suggests that this variant is damaging.

The proband underwent whole genome sequencing in 2021 at a different commercial laboratory to further investigate her extraocular features; this testing revealed only the novel variant in PAX6. 
Table 2. The proband's genetic findings

\begin{tabular}{|c|c|c|c|c|c|c|}
\hline Gene & Genomic location & HGVS cDNA & $\begin{array}{l}\text { HGVS } \\
\text { protein }\end{array}$ & Zygosity & $\begin{array}{l}\text { Parent of } \\
\text { origin }\end{array}$ & Variant interpretation \\
\hline PAX6 & $\begin{array}{l}\text { GRCh37/UCSC hg19 } \\
\text { Chr 11:31823288A > T }\end{array}$ & $\begin{array}{c}\text { NM_000280.3: } \\
\text { c. } 178 T>A\end{array}$ & p.Tyr60Asn & Heterozygous & Maternal & $\begin{array}{l}\text { Variant of uncertain significance, } \\
\text { reclassified as likely pathogenic } \\
\text { (PM1, PM2_P, PP3, PP4, PP1) }\end{array}$ \\
\hline
\end{tabular}

\section{VARIANT INTERPRETATION}

Variant p.Tyr60Asn is a novel missense variant in PAX6, located within the $\alpha-3$ helix, also known as the recognition helix, of the amino-terminal paired domain of the paired box 6 transcriptional regulator (amino acid residues 1-130) (Cross et al. 2020). This region was shown to make multiple contacts with DNA bases per analogous residues in the paired domain crystal structure (Xu et al. 1995). It is a known hotspot region in PAX6, where many pathogenic and likely pathogenic missense variants cluster (Cross et al. 2020). In silico analysis supports a deleterious effect on protein structure and function of this variant. The variant has not been observed in large population cohorts (gnomAD).

PAX6 variants are well-known for their effects on eye development, resulting in atrophy of the iris, nystagmus, foveal hypoplasia, cataracts, glaucoma, and corneal keratopathy (Lee et al. 2008; Lima Cunha et al. 2019). The genetic variant in the presented family would therefore explain their specific ocular medical history. Although childhood glaucoma is a potential postoperative complication of cataract surgery, the rate among this population $(<2 \mathrm{yr}$ old with bilateral congenital cataracts) is only 6.7\%, in a recent meta-analysis (Zhang et al. 2019). Given this complication's relative infrequency, and that congenital malformations related to PAX6 may promote glaucoma (Davis-Silberman et al. 2005), we suggest that the familial variant may have predisposed this family to developing glaucoma.

Additionally, patients with missense variants, like our patient and her family, often have a less severely affected iris (Lima Cunha et al. 2019). This could explain why the proband and her family do not have the complete aniridia associated with other PAX6 variants. Figure 2 displays a RetCam photograph of the proband's dilated eye exam under anesthesia.

Variants in PAX6 have also been associated with obesity and diabetes mellitus because of PAX6's role in pancreatic development (Panneerselvam et al. 2019; Boese et al. 2020); the familial variant, therefore, may have contributed to the brother's and mother's endocrinopathies. The mild neurodevelopmental differences found among affected individuals in this family may be explained by the PAX6 variant, given previous reported associations with neurodevelopmental abnormalities (Davis et al. 2008; Kikkawa et al. 2019). Furthermore, PAX6 haploinsufficiency has been reported to cause olfactory dysfunction, which may readily

\begin{tabular}{|c|c|c|c|c|}
\hline $\begin{array}{l}\text { Prediction } \\
\text { algorithm }\end{array}$ & Result & $\begin{array}{l}\text { Score or } \\
\text { probability }\end{array}$ & Range & References \\
\hline Provean & Damaging & -7.5 & $<-2.5$ is damaging & $\begin{array}{l}\text { Variant was run Provean; http://provean.jcvi } \\
\text {.org/about.php }\end{array}$ \\
\hline MutationTaster & Disease-causing & 0.978263334 & $\begin{array}{l}\text { Value close to } 1 \text { indicates high } \\
\text { security of the prediction }\end{array}$ & $\begin{array}{l}\text { MutationTaster; https://www.mutationtaster } \\
\text {.org/info/documentation.html }\end{array}$ \\
\hline PolyPhen-2 & Probably damaging & 1.0 & $\begin{array}{l}0.00-1.00, \text { with } 1.0 \text { disease- } \\
\text { causing }\end{array}$ & $\begin{array}{l}\text { PolyPhen; http://genetics.bwh.harvard.edu/ } \\
\text { pph2/dokuwiki/about }\end{array}$ \\
\hline
\end{tabular}




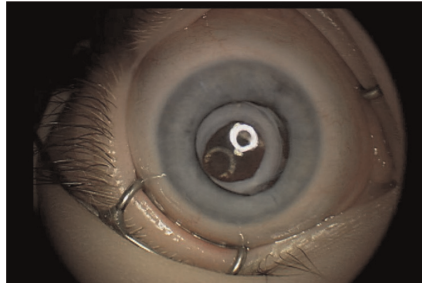

Figure 2. A RetCam photograph taken during a dilated exam under anesthesia of the proband's pupil and iris. Described clinically as iris stromal hypoplasia and slight pupil sphincter underdevelopment. A whitish Soemmering ring can be seen behind her intraocular lens implant, with a central opening.

explain the proband's and her mother's reports of diminished sense of smell (Sisodiya et al. 2001).

Collectively, considering the family's clinical findings and genetic testing results, we classify this variant as likely pathogenic.

\section{SUMMARY}

We describe a likely pathogenic variant in PAX6 present in three relatives with congenital cataracts and glaucoma at an early age. We suggest based on the current literature, clinical findings, and segregation among family members that this variant may be of clinical significance. Notably, the variant was discovered via NGS panel $4 \mathrm{yr}$ after an initially nondiagnostic result. A limitation of ophthalmologic gene panels is the frequency with which they are updated (Méjécase et al. 2020). This family highlights the need to consider retesting patients with nondiagnostic results-particularly those with family history indicating a genetic cause.

\section{ADDITIONAL INFORMATION}

\section{Data Deposition and Access}

This variant has been deposited in ClinVar (https://www.ncbi.nlm.nih.gov/clinvar/) under accession number SCV001906465.

\section{Ethics Statement}

All individuals provided consent for genetic testing, and affected individuals provided consent for inclusion in this manuscript.

\section{Acknowledgments}

We thank the proband and her family members for participating in this research. We also thank Dr. Sharon Freedman for her pediatric ophthalmology expertise and her clinical care of the proband and her family.

\section{Author Contributions}

Competing Interest Statement B.W. is an employee of GeneDx, Inc. The other authors have no conflicts of interest to disclose.

Received September 21, 2021; accepted in revised form December 9, 2021.
J.L.C. conceptualized and designed the study, obtained consent from individuals, and oversaw clinical data analysis and interpretation of genetic test results for the proband and family. K.L.B. performed the clinical data collection and analysis, conducted literature review, and wrote the initial manuscript draft. S.H. organized and facilitated the genetic testing as well as provided genetic counseling for the family. B.W. provided the genomic sequencing methods, data, and associated figures. All authors contributed to the editing of the manuscript and provided approval for the final version. 


\section{Funding}

Funding was provided by the Translating Duke Health-Children's Health \& Discovery Initiative.

\section{REFERENCES}

Boese EA, Tollefson MR, Schnieders MJ, Darbro BW, Alward WLM, Fingert JH. 2020. Novel intragenic PAX6 deletion in a pedigree with aniridia, morbid obesity, and diabetes. Curr Eye Res 45: 91-96. doi:10.1080/ 02713683.2019 .1649704

Cross E, Duncan-Flavell PJ, Howarth RJ, Crooks RO, Thomas NS, Bunyan DJ. 2020. Screening of a large PAX6 cohort identified many novel variants and emphasises the importance of the paired and homeobox domains. Eur J Med Genet 63: 103940. doi:10.1016/j.ejmg.2020.103940

Davis-Silberman N, Kalich T, Oron-Karni V, Marquardt T, Kroeber M, Tamm ER, Ashery-Padan R. 2005. Genetic dissection of Pax6 dosage requirements in the developing mouse eye. Hum Mol Genet 14: 2265-2276. doi:10.1093/hmg/ddi231

Davis LK, Meyer KJ, Rudd DS, Librant AL, Epping EA, Sheffield VC, Wassink TH. 2008. Pax6 3' deletion results in aniridia, autism and mental retardation. Hum Genet 123: 371-378. doi:10.1007/s00439-008-0484-x

Kikkawa T, Casingal CR, Chun SH, Shinohara H, Hiraoka K, Osumi N. 2019. The role of Pax6 in brain development and its impact on pathogenesis of autism spectrum disorder. Brain Res 1705: 95-103. doi:10.1016/j .brainres.2018.02.041

Lee H, Khan R, O'Keefe M. 2008. Aniridia: current pathology and management. Acta Ophthalmol 86: 708 715. doi:10.1111/j.1755-3768.2008.01427.x

Lima Cunha D, Arno G, Corton M, Moosajee M. 2019. The spectrum of PAX6 mutations and genotype-phenotype correlations in the eye. Genes (Basel) 10: 1050. doi:10.3390/genes10121050

Méjécase C, Malka S, Guan Z, Slater A, Arno G, Moosajee M. 2020. Practical guide to genetic screening for inherited eye diseases. Ther Adv Ophthalmol 12: 2515841420954592.

Panneerselvam A, Kannan A, Mariajoseph-Antony LF, Prahalathan C. 2019. PAX proteins and their role in pancreas. Diabetes Res Clin Pract 155: 107792. doi:10.1016/j.diabres.2019.107792

Sisodiya SM, Free SL, Williamson KA, Mitchell TN, Willis C, Stevens JM, Kendall BE, Shorvon SD, Hanson IM, Moore AT, et al. 2001. PAX6 haploinsufficiency causes cerebral malformation and olfactory dysfunction in humans. Nat Genet 28: 214-216. doi:10.1038/90042

Xie Q, Yang Y, Huang J, Ninkovic J, Walcher T, Wolf L, Vitenzon A, Zheng D, Götz M, Beebe DC, et al. 2013. Pax6 interactions with chromatin and identification of its novel direct target genes in lens and forebrain. PLoS ONE 8: e54507. doi:10.1371/journal.pone.0054507

Xu W, Rould MA, Jun S, Desplan C, Pabo CO. 1995. Crystal structure of a paired domain-DNA complex at $2.5 \AA$ resolution reveals structural basis for Pax developmental mutations. Cell 80: 639-650. doi:10.1016/00928674(95)90518-9

Zhang S, Wang J, Li Y, Liu Y, He L, Xia X. 2019. The role of primary intraocular lens implantation in the risk of secondary glaucoma following congenital cataract surgery: a systematic review and meta-analysis. PLoS ONE 14: e0214684. doi:10.1371/journal.pone.0214684 


\section{COLD SPRING HARBOR Molecular Case Studies}

\section{Novel PAX6 variant in a family with ophthalmologic, pancreatic, and olfactory features}

Kristen L. Buehne, Sarah Hart, Bradley Williams, et al.

Cold Spring Harb Mol Case Stud 2022, 8: a006149 originally published online December 10, 2021 Access the most recent version at doi: $10.1101 / \mathrm{mcs} . a 006149$

$\begin{array}{cl}\text { License } & \begin{array}{l}\text { This article is distributed under the terms of the Creative Commons } \\ \text { Attribution-NonCommercial License, which permits reuse and redistribution, except } \\ \text { for commercial purposes, provided that the original author and source are credited. }\end{array} \\ \text { Email Alerting } & \begin{array}{l}\text { Receive free email alerts when new articles cite this article - sign up in the box at the } \\ \text { Service right corner of the article or click here. }\end{array}\end{array}$

